\title{
EM Task 13 - Cone Penetrometer for Subsurface Heavy Metals Detection
}

\author{
Semi-Annual Report \\ April 1 - September 30, 1998
}

Ames A. Grisanti; Charlene R. Crocker

Work Performed Under Contract No.: DE-FC21-94MC31388

RECEIVFO

MAR 02 1994

OSTI

For

U.S. Department of Energy

Office of Fossil Energy

Federal Energy Technology Center

P.O. Box 880

Morgantown, West Virginia 26507-0880

By

Energy \& Environmental Research Center

University of North Dakota

P.O. Box 9018

Grand Forks, North Dakota 58202-9018 


\section{Disclaimer}

This report was prepared as an account of work sponsored by an agency of the United States Government. Neither the United States Government nor any agency thereof, nor any of their employees, makes any warranty, express or implied, or assumes any legal liability or responsibility for the accuracy, completeness, or usefulness of any information, apparatus, product, or process disclosed, or represents that its use would not infringe privately owed rights. Reference herein to any specific commercial product, process, or service by trade name, trademark, manufacturer, or otherwise does not necessarily constitute or imply its endorsement, recommendation, or favoring by the United States Government or any agency thereof. The views and opinions of authors expressed herein do not necessarily state or reflect those of the United States Government or any agency thereof. 


\section{DISCLAIMER}

Portions of this document may be illegible in electronic image products. Images are produced from the best available original document. 


\section{TABLE OF CONTENTS}

LIST OF FIGURES.

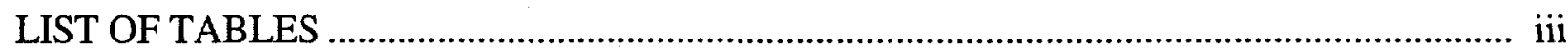

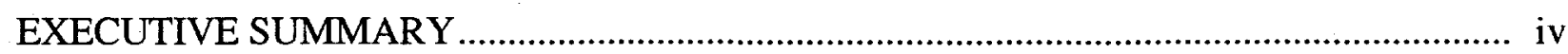

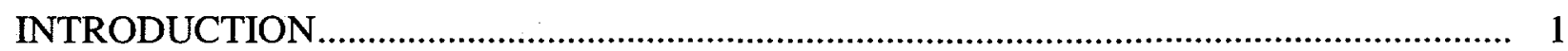

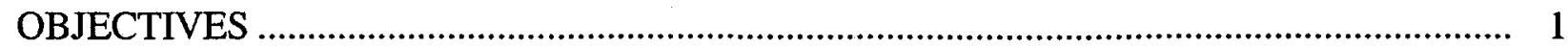

Laboratory Calibration of the LIBS Instrument ............................................................... 1

Preliminary Development of Multivariate Models............................................................... 2

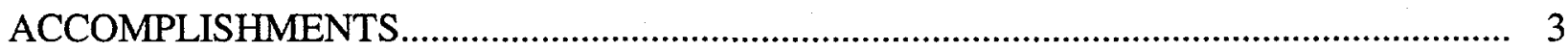

Calibration of a Portable LIBS Instrument ....................................................................... 3

LIBS-CPT Field Demonstration at Sandia National Laboratory....................................... 3

Task 1 - Laboratory Calibration of the LIBS Instrument................................................. 5

LIBS-CPT Calibration for Chromium in Sandia Soil - Conventional Approach.... 5

LIBS-CPT Calibration for Chromium in Sandia Soil - Improved Approach........... 7

SparkID Calibration for Chromium in Sandia Soil - Conventional Approach ........ 7

LIBS-SparkID Calibration for Chromium in Sandia Soil - Improved Approach ... 9

SparkID Calibration for Lead in Soil - Conventional Approach............................... 10

LIBS-SparkID Calibration for Lead in Soil - Improved Approach.......................... 11

Task 2 - Validation of LIBS Calibration................................................................... 13

Task 3 - Development of Multivariate Models for Subsurface Matrix Effects on the

LIBS Calibration.............................................................................................. 13

Development of PLS Regression-Based Calibrations ............................................ 13

PLS Calibration Example - Estimation of Pb in Soil Using the LIBS-SparkID ..... 14

FUTURE WORK

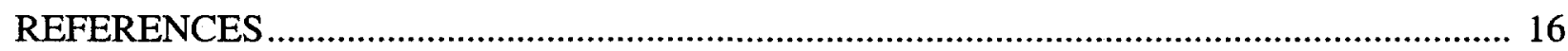




\section{LIST OF FIGURES}

1 Comparison of Sandia subsurface soil sample taken in situ at 8- $\mathrm{ft}$ depth (solid line) and Sandia surface soil sample taken ex situ (dotted line) using LIBS-CPT

2 Estimated $\mathrm{Cr}$ concentration versus depth at a Sandia National Laboratory landfill site measured in situ with LIBS-CPT

3 Typical LIBS-CPT spectrum of Sandia soil Cr calibration sample

4 Predicted versus actual $\mathrm{Cr}$ concentration for conventional LIBS-CPT calibration approach (Sandia soil samples)

5 Predicted versus actual Cr concentration for improved LIBS-CPT calibration approach (Sandia soil samples)

6 Typical LIBS-SparkID spectrum of Sandia soil Cr calibration sample.

7 Predicted versus actual $\mathrm{Cr}$ concentration for conventional LIBS-SparkID calibration approach (Sandia soil samples)

8 Predicted versus actual $\mathrm{Cr}$ concentration for improved LIBS-SparkID calibration approach (Sandia soil samples).

9 LIBS-SparkID spectrum for a $\mathrm{Pb}$ calibration sample

10 Region of interest for development of LIBS-SparkID calibration for $\mathrm{Pb}$ in soil

11 Comparison of conventional and improved methods for prediction of $\mathrm{Pb}$ concentration in soil by LIBS-SparkID

12 PRESS results for $\mathrm{Pb}$ in soil calibration by PLS 15

13 First two loadings from $\mathrm{PLS}$ regression of $\mathrm{Pb}$ calibration samples...... 15 


\section{LIST OF TABLES}

$1 \quad \mathrm{Cr}$ and Fe Concentration in LIBS Soil Calibration Samples ........................................ 6

$2 \quad \mathrm{~Pb}$ Concentration in LIBS Soil Calibration Samples....................................................... 11 


\section{EM TASK 13 - CONE PENETROMETER FOR SUBSURFACE HEAVY METALS DETECTION}

\section{EXECUTIVE SUMMARY}

Laser-induced breakdown spectroscopy (LIBS) has been used to successfully measure metals content in a variety of matrices including soil. Under the U.S. Department of Energy Federal Energy Technology Center (DOE FETC) Industry Program, Science \& Engineering Associates (SEA) is developing a subsurface cone penetrometer (CPT) probe for heavy metals detection that employs LIBS. The LIBS-CPT unit is to be applied to in situ, real-time sampling and analysis of heavy metals in soil. As part of its contract with DOE FETC, SEA is to do a field demonstration of its LIBS-CPT system at a DOE facility. SEA has requested technical assistance from the Energy \& Environmental Research Center (EERC) under the DOE FETC-EERC Environmental Management Cooperative Agreement.

The overall objectives of this project are to evaluate potential calibration techniques for the LIBS-CPT instrument, provide a preliminary evaluation of the LIBS instrument calibration using samples obtained from the field, and provide technical support to field demonstration of the LIBS-CPT instrument at a DOE facility.

Work during this reporting period completed calibration of the LIBS instrument and preliminary development of multivariate models for subsurface matrix effects on LIBS calibrations. In addition, EERC personnel assisted SEA in a field demonstration of the LIBSCPT instrument at Sandia National Laboratory. Confirmation of the LIBS calibration will be completed and documented during the next reporting period.

EERC personnel worked with SEA and Sandia personnel over the week of July 13,1998, on a field demonstration of the LIBS-CPT system at the Area 111 Chemical Waste Landfill at Sandia National Laboratory. The application of the LIBS-CPT unit was to perform a subsurface survey for chromium contamination in the soil. Several personnel involved in environmental restoration (ER) activities at DOE facilities witnessed the field demonstration. Overall, the field demonstration was a success. The LIBS-CPT instrument was able to detect and estimate quantities of chromium in the subsurface at the Sandia landfill site.

Laboratory work on LIBS calibration and testing included work on a portable LIBS instrument in addition to that carried out on the LIBS-CPT equipment. SEA has loaned equipment to the EERC consisting of an Nd-YAG laser, spectrograph, diode array detector, and optical components. Prior work done by SEA has integrated the components on loan to the EERC into a portable system with a prototype LIBS probe for use in surface measurements in the field. SEA has labeled the portable LIBS system the SparkID. Work done at the EERC on the SparkID system has resulted in an improved design for the LIBS probe.

Laboratory calibration work focused on chromium and lead in soil. Calibrations for both the LIBS-CPT (cone penetrometer delivered) and the LIBS-SparkID (portable unit for ex situ 
application) instruments were developed. Improved LIBS calibration techniques were developed in this work for field applications.

Continuation of work in this project will involve completion of calibration validation and development of improved calibration methods for application of LIBS in field screening applications. 


\section{EM TASK 13 - CONE PENETROMETER FOR SUBSURFACE HEAVY METALS DETECTION}

\section{INTRODUCTION}

Surface and subsurface contamination of soils by heavy metals, including $\mathrm{Pb}, \mathrm{Cr}, \mathrm{Cu}, \mathrm{Zn}$, and $\mathrm{Cd}$ has become an area of concern for many industrial and government organizations (1). Conventional sampling and analysis techniques for soil provide a high degree of sensitivity and selectivity for individual analytes. However, obtaining a representative sampling and analysis from a particular site using conventional techniques is time consuming and costly (2). Additionally, conventional methods are difficult to implement in the field for in situ and/or realtime applications. Therefore, there is a need for characterization and monitoring techniques for heavy metals in soils that allow cost-effective, rapid, in situ measurements.

Laser-induced breakdown spectroscopy (LIBS) has been used to successfully measure metals content in a variety of matrices (3-15) including soil $(16,17)$. Under the U.S. Department of Energy Federal Energy Technology Center (DOE FETC) Industry Program, Science \& Engineering Associates (SEA) is developing a subsurface cone penetrometer (CPT) probe for heavy metals detection that employs LIBS (18). The LIBS-CPT unit is to be applied to in situ, real-time sampling and analysis of heavy metals in soil. As part of its contract with DOE FETC, SEA is to do a field demonstration of its LIBS-CPT system at a DOE facility.

\section{OBJECTIVES}

The overall objectives of this project are to evaluate potential calibration techniques for the LIBS-CPT instrument, to provide a preliminary evaluation of the LIBS instrument calibration using samples obtained from the field and to provide technical support to field demonstration of the LIBS-CPT instrument at a DOE facility.

\section{Laboratory Calibration of the LIBS Instrument}

The objectives of this activity are to 1) investigate methods of preparing soil mixtures in the laboratory which approximate soil samples that are encountered during in situ analysis and 2) test new calibration procedures for the LIBS instrument. Information on available field test sites for the LIBS instrument will be surveyed to gather information on soil physical and chemical properties. A field site will be selected and soil mixtures will be prepared in the laboratory to represent field conditions. The Energy \& Environmental Research Center (EERC) will prepare a suite of soil samples that provides statistical representation of the range of sample matrix effects parameterizing on the following variables: grain size, moisture, $\mathrm{pH}$, humic matter, and heavy metals. The heavy metals in the matrix will give statistical representation of the metals present at the field test site, $\mathrm{Cr}, \mathrm{As}, \mathrm{Cd}, \mathrm{Cu}, \mathrm{Pb}, \mathrm{Mg}, \mathrm{Mn}$ and $\mathrm{Zn}$. This set of samples along with a complete set of data will be submitted to SEA for use in calibrating the LIBS-CPT probe. EERC personnel will then obtain a representative sampling of soil from the test site. The set of samples collected in the field will be characterized in the EERC laboratories for the variables listed 
above. Particular attention will be paid to the determination of metals content, since this is the most important aspect of the calibration and validation. The metals in soil will be determined by inductively coupled plasma spectroscopy (ICP), graphite furnace atomic absorption spectroscopy (GFAAS), and/or wavelength-dispersive X-ray fluorescence (WDXRF) in the EERC laboratories. A random sampling of the data collected at the EERC will be validated using an external laboratory. A random selection from the original calibration set and the samples obtained from the field will be provided to SEA without any data. SEA will analyze the samples using the calibrated LIBS-CPT probe and submit the data to the EERC. EERC personnel will compute calibration statistics and report the precision and accuracy of the calibration to SEA. If necessary, calibration techniques will be adjusted until an acceptable level of precision and accuracy is achieved.

\section{Preliminary Development of Multivariate Models}

Activities under this task are to investigate methods of correcting LIBS instrument responses for sample matrix effects with the goal of obtaining calibration techniques which can be used under a variety of soil chemical and physical property conditions. Multivariate statistical analysis techniques such as principal component analysis (PCA) will be applied to the data collected during the laboratory calibration and validation to obtain information on the matrix effects which most influence the quantitation of heavy metals in the soil. Different calibration techniques will be evaluated in order to develop a data analysis technique which provides a robust means of analyzing the data obtained from the LIBS-CPT probe to extract quantitative or semiquantitative data on heavy metals, which is insensitive to sample matrix effects. Statistical outlier detection methods will also be applied in the data analysis to develop diagnostic techniques for application to data in the field, allowing quality control of reported heavy metal quantities.

The project is broken down by task as follows:

- Task 1 - Laboratory Calibration of the LIBS Instrument

- Task 1.1 - Definition of laboratory-prepared soil sample matrix

- Task 1.2 - Laboratory preparation of soil samples

- Task 1.3 - LIBS data collection

- Task 1.4 - Data reduction and analysis

- Task 2 - Validation of LIBS Calibration

- Task 2.1 - Field sample collection

- Task 2.2 - Field sample characterization

- Task 2.3 - LIBS data collection

- Task 2.4 - Data reduction and analysis

- Task 3 - Development of multivariate models for subsurface matrix effects on the LIBS calibration 


\section{ACCOMPLISHMENTS}

Work during this reporting period completed Tasks 1 and 3. In addition, EERC personnel assisted SEA in a field demonstration of the LIBS-CPT instrument at Sandia National Laboratory. Task 2 will be completed and documented during the next reporting period.

\section{Calibration of a Portable LIBS Instrument}

Laboratory work on LIBS calibration and testing included work on a portable LIBS instrument in addition to that carried out on the LIBS-CPT equipment. SEA has loaned equipment to the EERC consisting of an Nd-YAG laser, spectrograph, diode array detector, and optical components. Prior work done by SEA has integrated the components on loan to the EERC into a portable system with a prototype LIBS probe for use in surface measurements in the field. SEA has labeled the portable LIBS system the SparkID. Work done at the EERC on the SparkID system has resulted in an improved design for the LIBS probe. In addition, extensive work has been done with the SparkID to evaluate calibration techniques for measurement of metals in soils. Therefore, work done in Tasks 1 through 3 was carried out in parallel on the LIBS-CPT and SparkID instruments. SEA personnel carried out LIBS data collection work with the LIBS-CPT, while EERC personnel collected similar data using the SparkID. Details of the calibration work done with the SparkID instrument are described in the sections documenting work under Tasks 1,2 , and 3.

\section{LIBS-CPT Field Demonstration at Sandia National Laboratory}

EERC personnel worked with SEA and Sandia personnel over the week of July 13, 1998, on a field demonstration of the LIBS-CPT system at the Area 111 Chemical Waste Landfill at Sandia National Laboratory. The application of the LIBS-CPT unit was to perform a subsurface survey for chromium contamination in the soil. Several personnel involved in environmental restoration (ER) activities at DOE facilities witnessed the field demonstration. ER personnel present at the test included Jim Phelan and Bob Helgeson of Sandia National Laboratory, John April of Bechtel Hanford, and Jim Studer of Duke Energy, a contractor working at Sandia. In addition, the FETC project manager for the LIBS-CPT project, Karen Cohen, was present.

The LIBS-CPT instrument was applied in an area of the landfill that was previously sampled by taking core sections from a borehole and subjecting the samples to laboratory analysis by GFAAS and/or ICP. Data supplied by Sandia National Laboratory personnel which were collected by conventional means indicate that the total chromium concentration varies over a range of approximately 50 to $2500 \mathrm{ppm}$ (by weight) at 10 - to 20 -feet depths. Additionally, data from the previous conventional measurements show that the iron concentration over the 10- to 20 -foot depth ranges from 10 to $20 \mathrm{ppm}$. The LIBS-CPT probe was pushed into the ground and spectra collected as the probe was withdrawn from the subsurface. Typically, the LIBS-CPT probe collected a spectrum approximately every 0.1 ".

Overall, the field demonstration was a success. The LIBS-CPT instrument was able to detect and estimate quantities of chromium in the subsurface at the Sandia landfill site. Figure 1, 
compares a LIBS spectrum of subsurface soil taken in situ to a surface soil sample measured ex situ at the Sandia landfill site.

In order to compare the amount of chromium in the subsurface soil to that in the surface soil, the intensity ( $\mathrm{Y}$-axis) values of the surface soil spectrum in Figure 1 were scaled. Spectrum intensity scaling was done to make the iron peaks $(428.25,430.73,432.53$, and $438.36 \mathrm{~nm})$ in the surface soil spectrum equal to those in the subsurface soil spectrum. Of course this assumes that the iron concentration is constant in the two samples depicted in Figure 1. As mentioned above, conventional sampling and analysis of core samples taken from a borehole near the LIBS-CPT sampling point indicate that the iron concentration varies only about $10 \mathrm{ppm}$. Therefore, the assumption of constant iron concentration is justified for practical purposes. The level of chromium in the soil at a depth of 8 feet is quite a bit higher than the level at the surface. This is indicated by the increased intensity of the emissions measured in the $\mathrm{Cr}$ peaks $(425.45,427.49$, $433.91,434.42,435.3$, and $437.11 \mathrm{~nm}$ ) by the LIBS-CPT probe as shown in Figure 1.

The LIBS-CPT probe was calibrated using procedures described in the sections documenting work done under Tasks 1,2, and 3 below. Figure 2 shows a plot of $\mathrm{Cr}$ concentration versus depth developed from LIBS-CPT data using an improved calibration technique developed at the EERC.

A total of 955 spectra were taken over the interval of 6 to 8 feet to make up the plot of Figure 2. The gaps in the data result from spectra that were excluded from the analysis on the basis of a new spectrum quality test developed at the EERC. The spectrum quality test is a data selection method that will qualify new data prior to estimation of analyte quantities $(\mathrm{Cr}$ in this case).

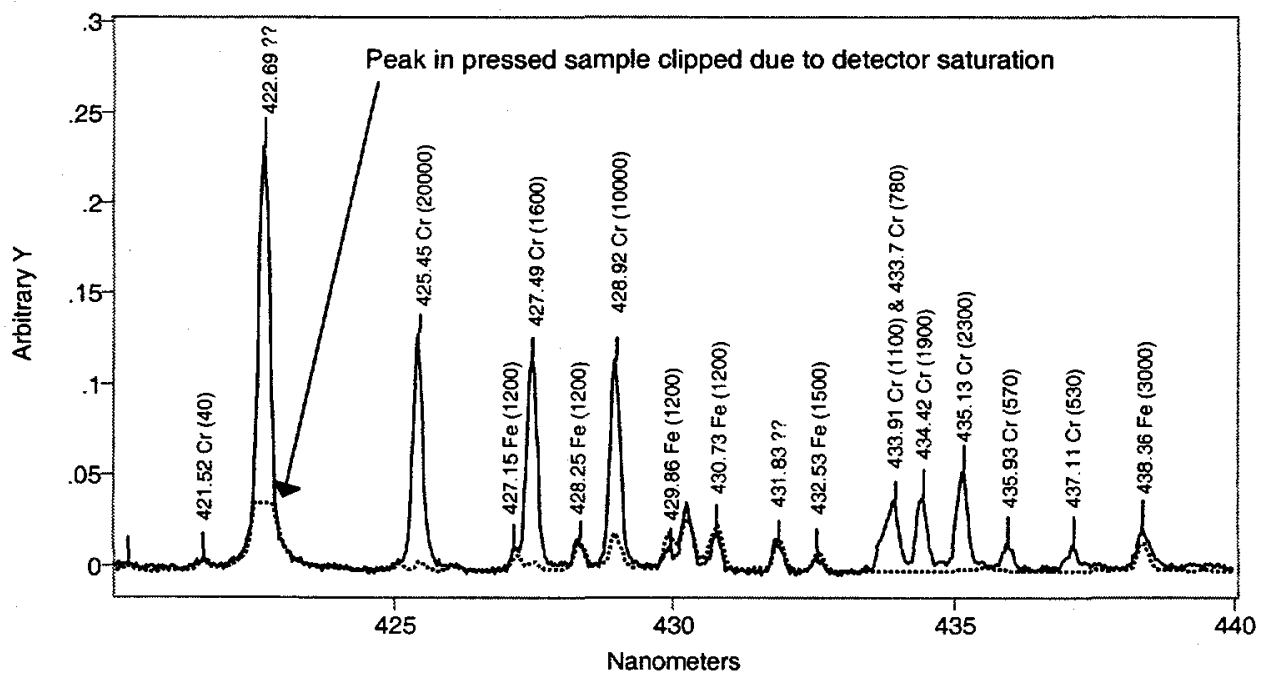

Figure 1. Comparison of Sandia subsurface soil sample taken in situ at 8-ft. depth (solid line) and Sandia surface soil sample taken ex situ (dotted line) using the LIBS-CPT. 


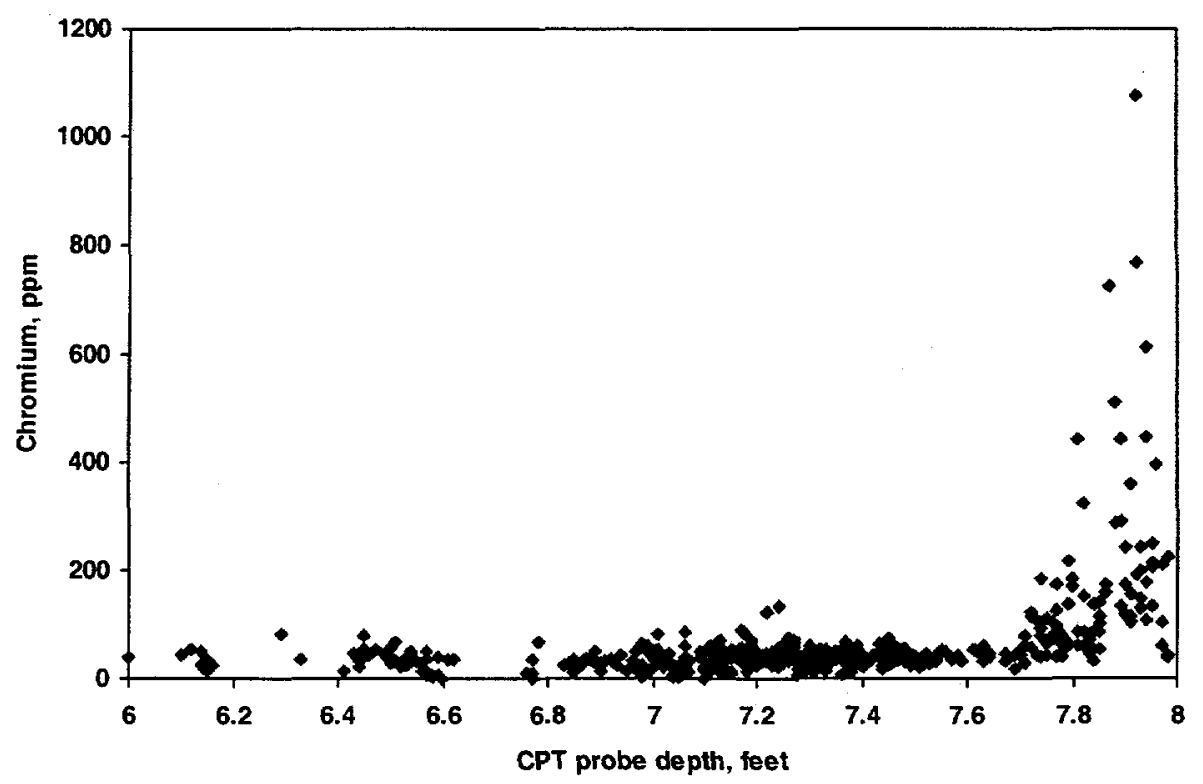

Figure 2. Estimated Cr concentration versus depth at a Sandia National Laboratory landfill site measured in situ with LIBS-CPT.

\section{Task 1 - Laboratory Calibration of the LIBS Instrument}

Laboratory calibration work focused on chromium and lead in soil. Calibrations for both the LIBS and the LIBS/SparkID instruments were developed.

\section{LIBS-CPT Calibration for Chromium in Sandia Soil - Conventional Approach}

Calibration was accomplished by collecting LIBS instrument response data for samples of Sandia soil spiked with chromium. Spiked soil samples were prepared from Sandia surface soil using procedures developed and documented in a previous report (18-20). Chromium concentration in each of the soil samples to be used for calibration was verified by conventional analysis techniques as applied previously in this work (18-20). Table 1 lists the amount of $\mathrm{Cr}$ added to the baseline soil for each of the calibration samples along with the actual concentration. LIBS data on each of the calibration samples listed in Table 1 were collected consisting of 250 spectra where each is the emission resulting from a single laser spark. Computing an average spectrum for each of the spiked soil samples from the 250 single-spark spectra developed the LIBS instrument calibration for Cr. Figure 3 shows an average LIBS spectrum for one of the $\mathrm{Cr}$ calibration samples.

Calibration information was extracted from the spiked soil sample set by integrating the peak area of two of the Cr peaks (425.45 and $427.49 \mathrm{~nm}$ ), and as a reference, the area of an Fe peak $(438.36 \mathrm{~nm})$ was integrated. The calibration derived from the sample set provided an extremely nonlinear relationship between instrument response and $\mathrm{Cr}$ concentration as depicted in Figure 4 . 


\section{TABLE 1}

$\mathrm{Cr}$ and Fe Concentration in LIBS Soil Calibration Samples

\begin{tabular}{lccc}
\hline & $\begin{array}{c}\mathrm{Cr} \\
\text { Added, } \\
\mu \mathrm{g} / \mathrm{g}\end{array}$ & $\begin{array}{c}\text { Actual Cr } \\
\text { Concentration, } \\
\mu \mathrm{g} / \mathrm{g}\end{array}$ & $\begin{array}{c}\text { Actual Fe } \\
\text { Concentration, } \\
\%\end{array}$ \\
\hline Sample & 0 & 30 & 13.4 \\
Sandia Baseline Soil & 50 & 77 & 14.6 \\
Sandia Soil No. 101 & 100 & 130 & 15.4 \\
Sandia Soil No. 102 & 200 & 220 & 15.0 \\
Sandia Soil No. 103 104 & 300 & 300 & 14.4 \\
Sandia Soil No. 105 & 500 & 390 & 14.2 \\
Sandia Soil No. 106 & 1000 & 890 & 14.6 \\
Sandia Soil No. 107 & 2000 & 1840 & 14.6 \\
Sandia Soil No. 108 & 5000 & 4560 & 14.4 \\
Sandia Soil No. 109 & 25 & 54 & 14.8 \\
\hline
\end{tabular}

Further attempts to extract instrument response data such as using peak height or ratios of Fe to $\mathrm{Cr}$ peak areas (or heights) gave similar relationships to actual $\mathrm{Cr}$ concentration as shown in Figure 4.

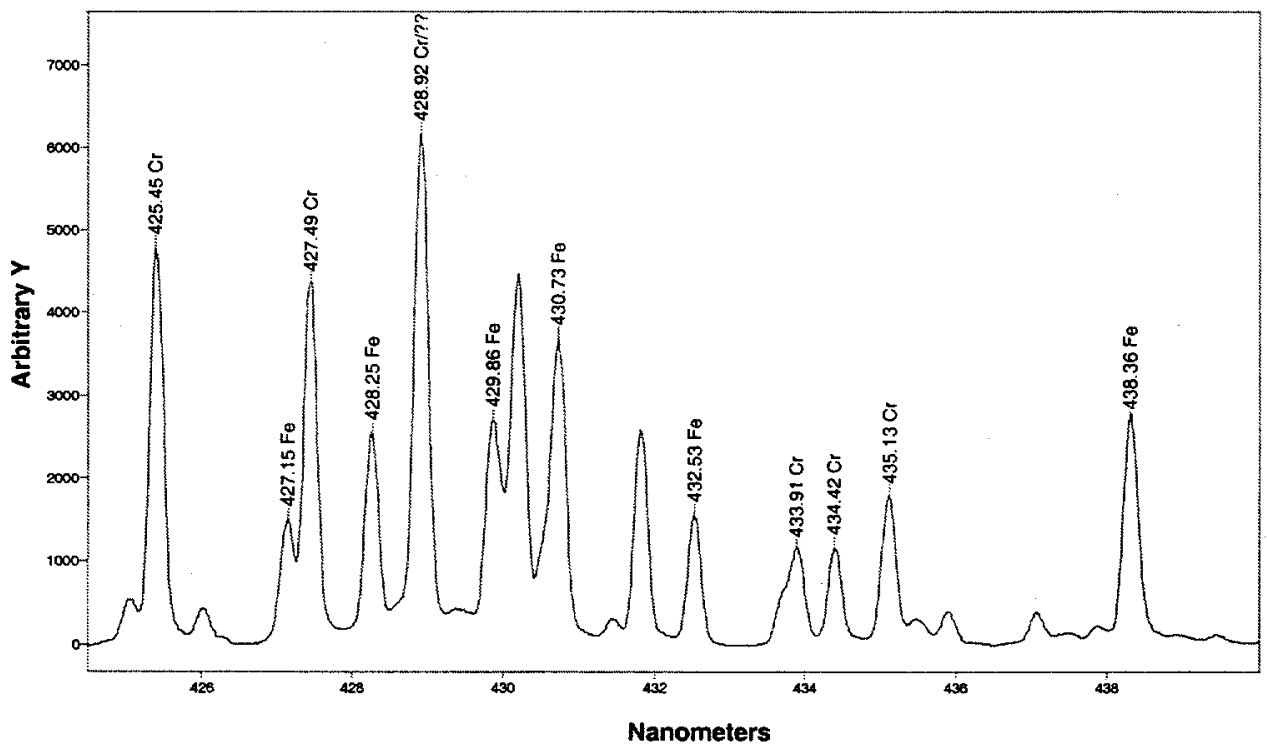

Figure 3. Typical LIBS-CPT spectrum of Sandia soil Cr calibration sample. 


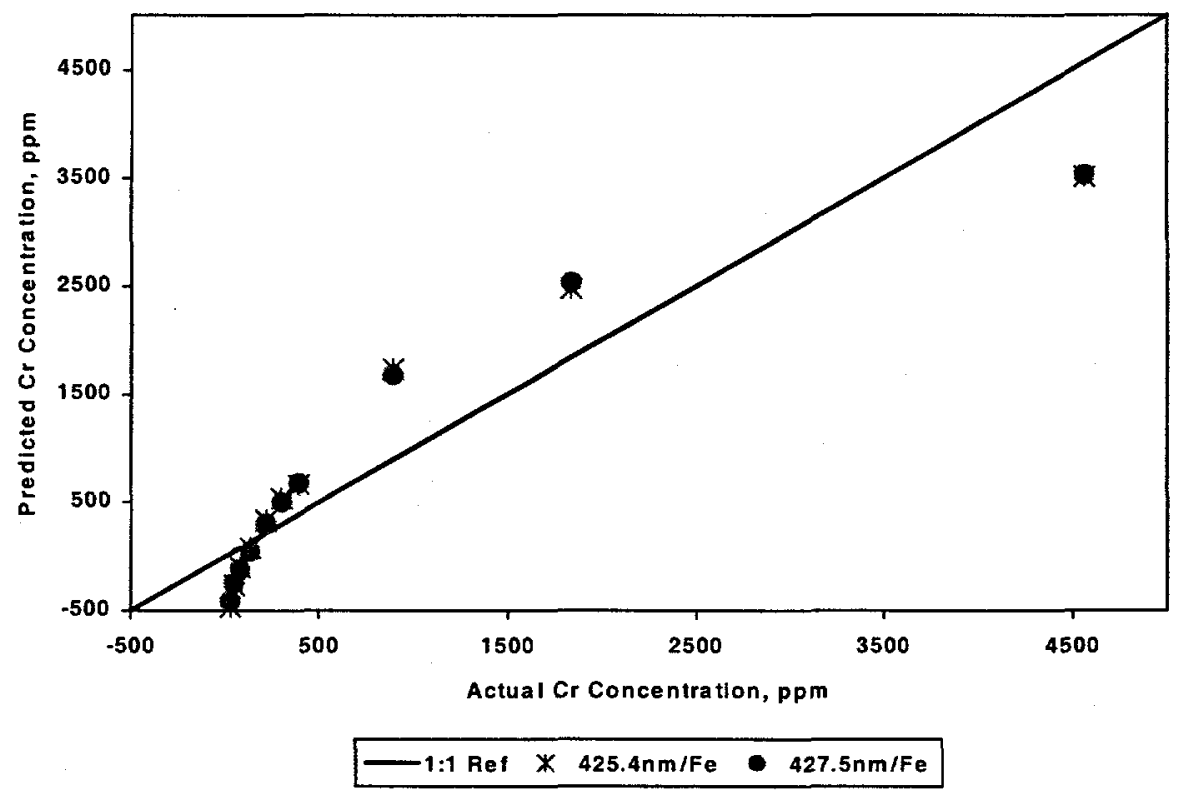

Figure 4. Predicted versus actual $\mathrm{Cr}$ concentration for conventional LIBS-CPT calibration approach (Sandia soil samples).

\section{LIBS-CPT Calibration for Chromium in Sandia Soil - Improved Approach}

An improvement in the calibration for the LIBS-CPT instrument was accomplished by application of work done in Task 3 on multivariate calibration techniques. For the application of the LIBS-CPT to measurement of $\mathrm{Cr}$ in soil, a full-spectrum calibration model was developed using the Sandia soil calibration set listed in Table 1. The calibration model was developed using partial least squares (PLS) regression techniques. Improved LIBS calibration techniques based on PLS regression use the entire measured spectrum (700 to 1000 wavelength data points) for each sample to predict analyte concentration. Conventional LIBS calibration techniques rely on a single analyte peak (typically 15 to 25 wavelength data points) to predict the concentration in samples. Figure 5 shows a LIBS calibration model for Cr in Sandia soil using PLS regression. Comparison of the conventional (Figure 4) versus the PLS approach (Figure 5) to calibration shows a significant improvement in the ability of the LIBS-CPT to estimate the quantity of $\mathrm{Cr}$ in Sandia soil over a wide range of concentration ( 15 to $4500 \mathrm{ppm}$ ).

\section{SparkID Calibration for Chromium in Sandia Soil - Conventional Approach}

A calibration was developed for the SparkID (portable LIBS instrument) by collecting LIBS instrument response data for the same samples of Sandia soil spiked with chromium used in the LIBS-CPT calibration study. Table 1 lists the amount of $\mathrm{Cr}$ added to the baseline soil for each of the calibration samples along with the actual concentration. LIBS data on each of the calibration samples listed in Table 1 were collected consisting of 25 spectra where each is the 


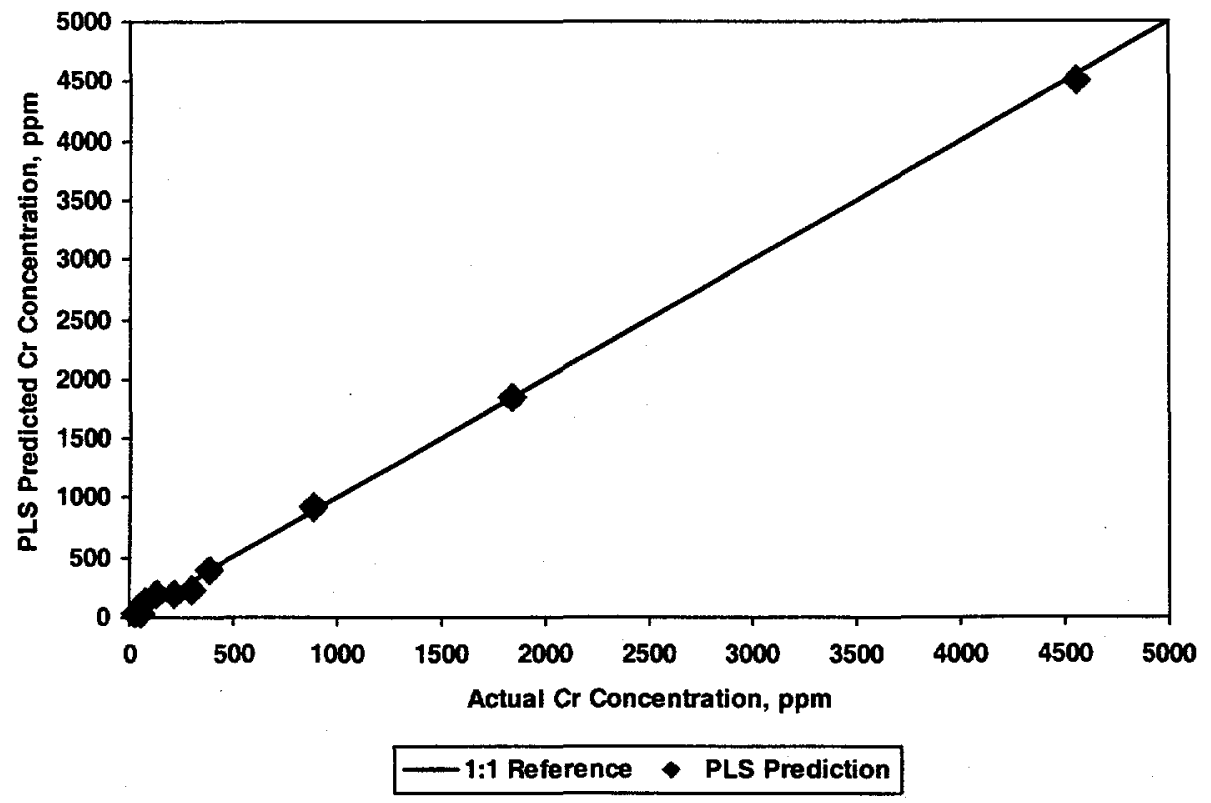

Figure 5. Predicted versus actual $\mathrm{Cr}$ concentration for improved LIBS-CPT calibration approach (Sandia soil samples).

emission resulting from a single laser spark. Computing an average spectrum for each of the spiked soil samples from the 25 single-spark spectra developed the LIBS instrument calibration for Cr. A typical Sandia soil LIBS spectrum obtained with the SparkID instrument is shown in Figure 6.

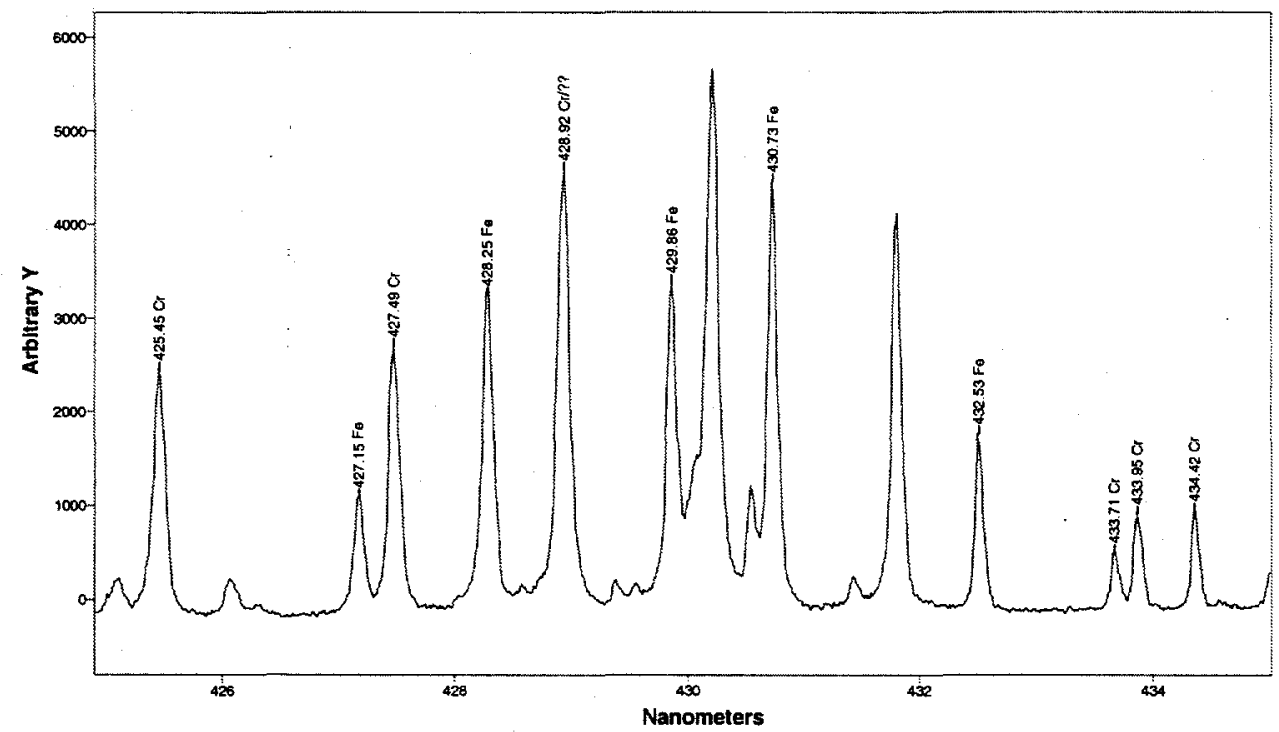

Figure 6. Typical LIBS-SparkID spectrum of Sandia soil Cr calibration sample. 
Calibration information was extracted from the spiked soil sample set by integrating the peak area of two of the Cr peaks (425.45 and $427.49 \mathrm{~nm}$ ), and as a reference, the area of an Fe peak $(432.53 \mathrm{~nm})$ was integrated. The calibration derived from the sample gave a relationship between instrument response and $\mathrm{Cr}$ concentration as depicted in Figure 7. Further attempts to extract instrument response data such as using peak height or ratios of $\mathrm{Fe}$ to $\mathrm{Cr}$ peak areas (or heights) gave similar relationships to actual $\mathrm{Cr}$ concentration as shown in Figure 7 . As with the LIBS-CPT calibration, the relationship of instrument response to actual $\mathrm{Cr}$ concentration in the soil is not linear.

\section{LIBS-SparkID Calibration for Chromium in Sandia Soil - Improved Approach}

An improvement in the calibration for the LIBS-SparkID instrument was accomplished by application of work done in Task 3 on multivariate calibration techniques. For the application of the LIBS-SparkID to measurement of $\mathrm{Cr}$ in soil, a full-spectrum calibration model was developed using the Sandia soil calibration set listed in Table 1. The calibration model was developed using PLS regression techniques. Improved LIBS calibration techniques based on PLS regression use the entire measured spectrum ( 700 to 1000 wavelength data points) for each sample to predict analyte concentration. Conventional LIBS calibration techniques rely on a single analyte peak (typically 15 to 25 wavelength data points) to predict the concentration in samples. Figure 8 shows a LIBS calibration model for $\mathrm{Cr}$ in Sandia soil using PLS regression. Comparison of the conventional (Figure 7) versus the PLS approach (Figure 8) to calibration shows a significant improvement in the ability of the LIBS-SparkID to estimate the quantity of $\mathrm{Cr}$ in Sandia soil over a wide range of concentration (15 to $4500 \mathrm{ppm}$ ).

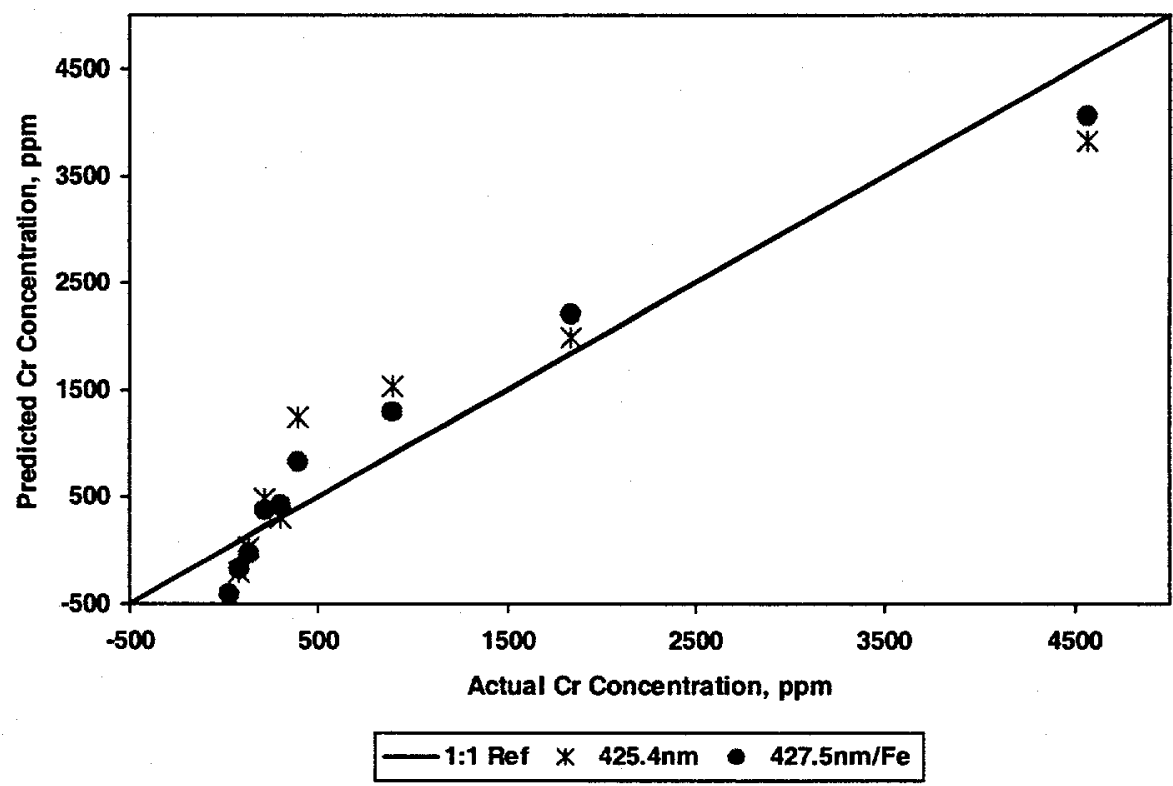

Figure 7. Predicted versus actual Cr concentration for conventional LIBS-SparkID calibration approach (Sandia soil samples). 


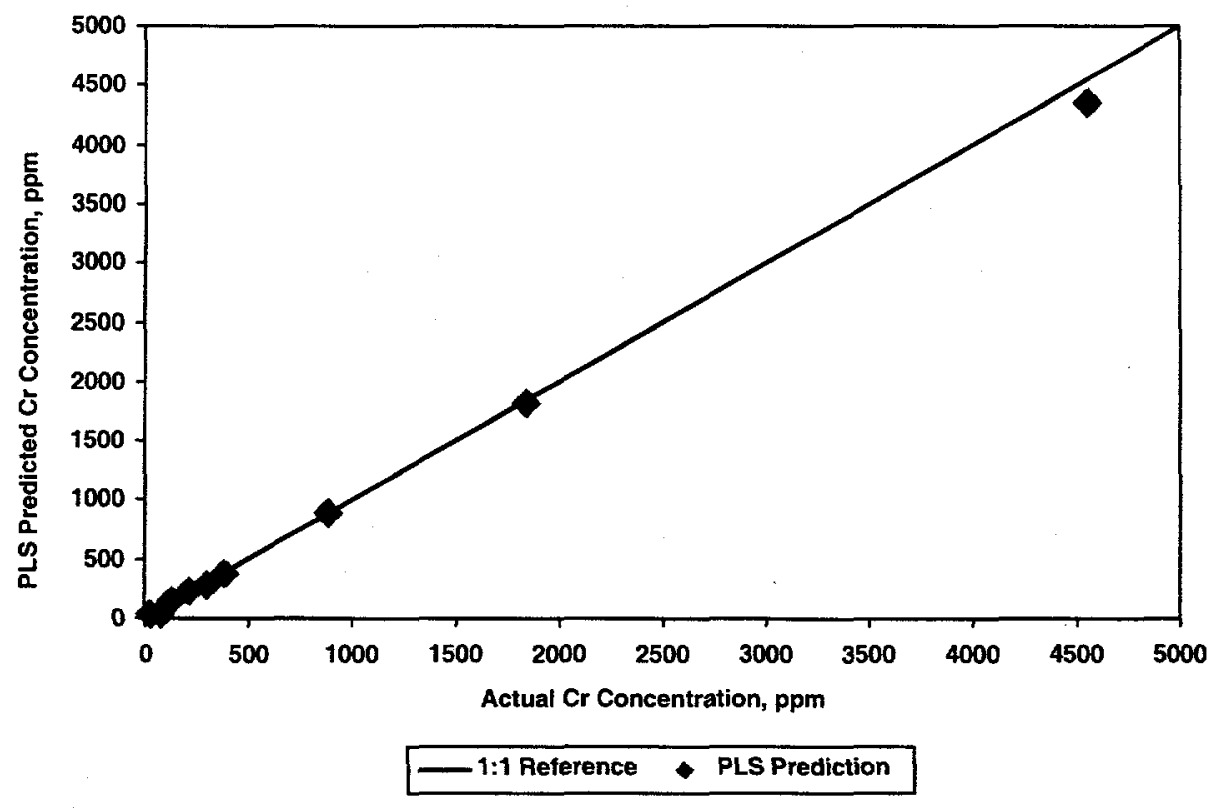

Figure 8. Predicted versus actual Cr concentration for improved LIBS-SparkID calibration approach (Sandia soil samples).

\section{SparkID Calibration for Lead in Soil - Conventional Approach}

Calibration was accomplished by collecting LIBS-SparkID instrument response data for soil samples obtained from northern Minnesota that have a known grain-size distribution, are, for purposes of this study, free of metals contamination (Tanberg soil), and have been spiked with lead. Collection, preparation, and characterization of the Tanberg soil was described in a previous report (18-20). The spiked soil samples were prepared from the baseline Tanberg soil using procedures developed and documented in a previous report (18-20). Lead concentration in each of the soil samples to be used for calibration was verified by conventional analysis techniques as applied previously in this work (18-20). Table 2 lists the amount of $\mathrm{Pb}$ added to the baseline soil for each of the calibration samples along with the actual concentration. LIBS data on each of the calibration samples listed in Table 2 were collected consisting of 25 spectra, where each is the emission resulting from a single laser spark. Computation of an average spectrum for each of the spiked soil samples from the 25 single-spark spectra provided the LIBS-SparkID instrument calibration data for $\mathrm{Pb}$. Figure 9 shows an average LIBS-SparkID spectrum for one of the $\mathrm{Pb}$ calibration samples.

Calibration information was extracted from the spiked soil sample set by integrating the peak area of a $\mathrm{Pb}$ peak at $368.1 \mathrm{~nm}$. Figure 10 shows an expanded view of the $368-\mathrm{nm} \mathrm{Pb}$ peak region for each of the calibration samples. Figure 11 illustrates the ability of peak area to predict the concentration of $\mathrm{Pb}$ in the soil. As can be seen in Figure 11, the calibration does not accurately predict the $\mathrm{Pb}$ concentration for concentrations above $200 \mathrm{ppm}$. 
TABLE 2

$\mathrm{Pb}$ Concentration in LIBS Soil Calibration Samples

Actual $\mathrm{Pb}$

Concentration,

Sample

Tanberg 88 $\mu \mathrm{g} / \mathrm{g}$

Tanberg 86 24.3

Tanberg 85

48.6

Tanberg 83

121.5

Tanberg 87

243

Tanberg 84

607.5

Tanberg 28

1215

\section{LIBS-SparkID Calibration for Lead in Soil - Improved Approach}

As with the previous calibrations, the improved approach of using the entire spectrum to calibrate the SparkID instrument was done using PLS regression. As can be seen in Figure 11,

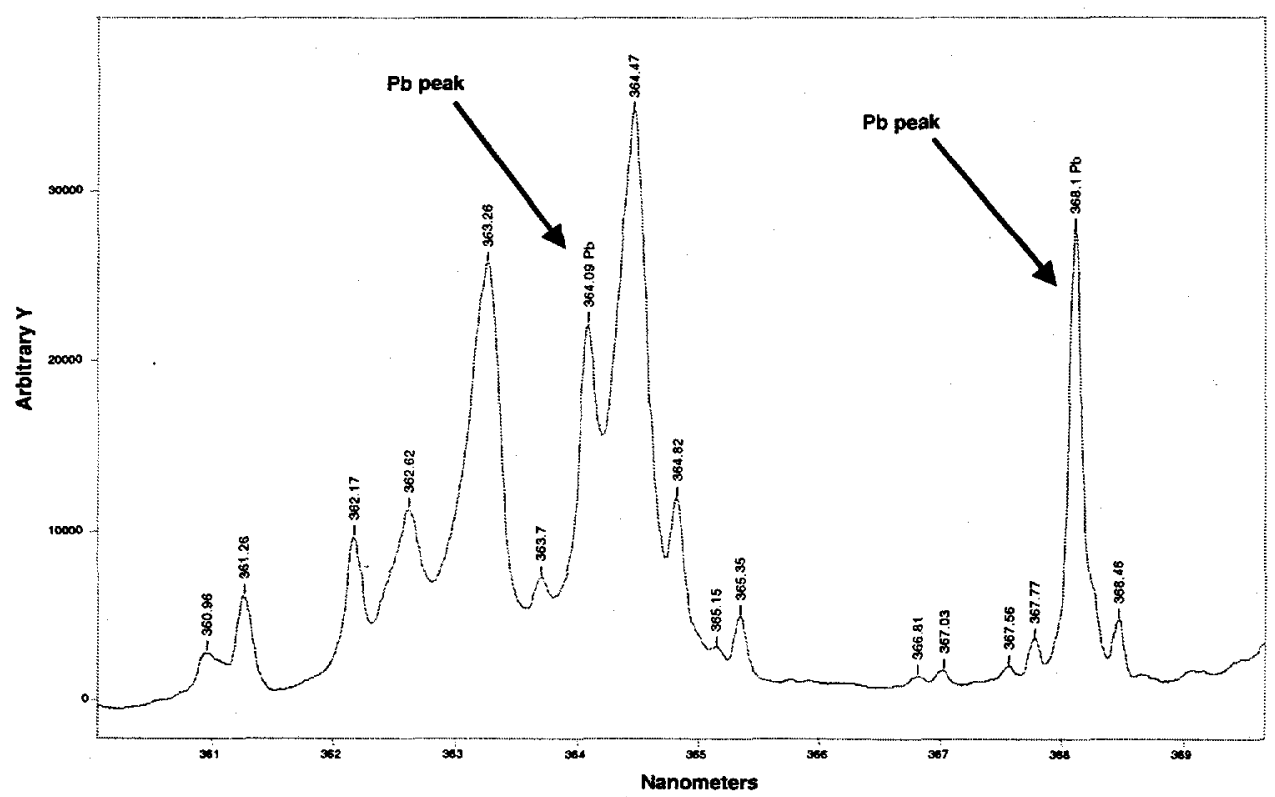

Figure 9. LIBS-SparkID spectrum for a $\mathrm{Pb}$ calibration sample. 


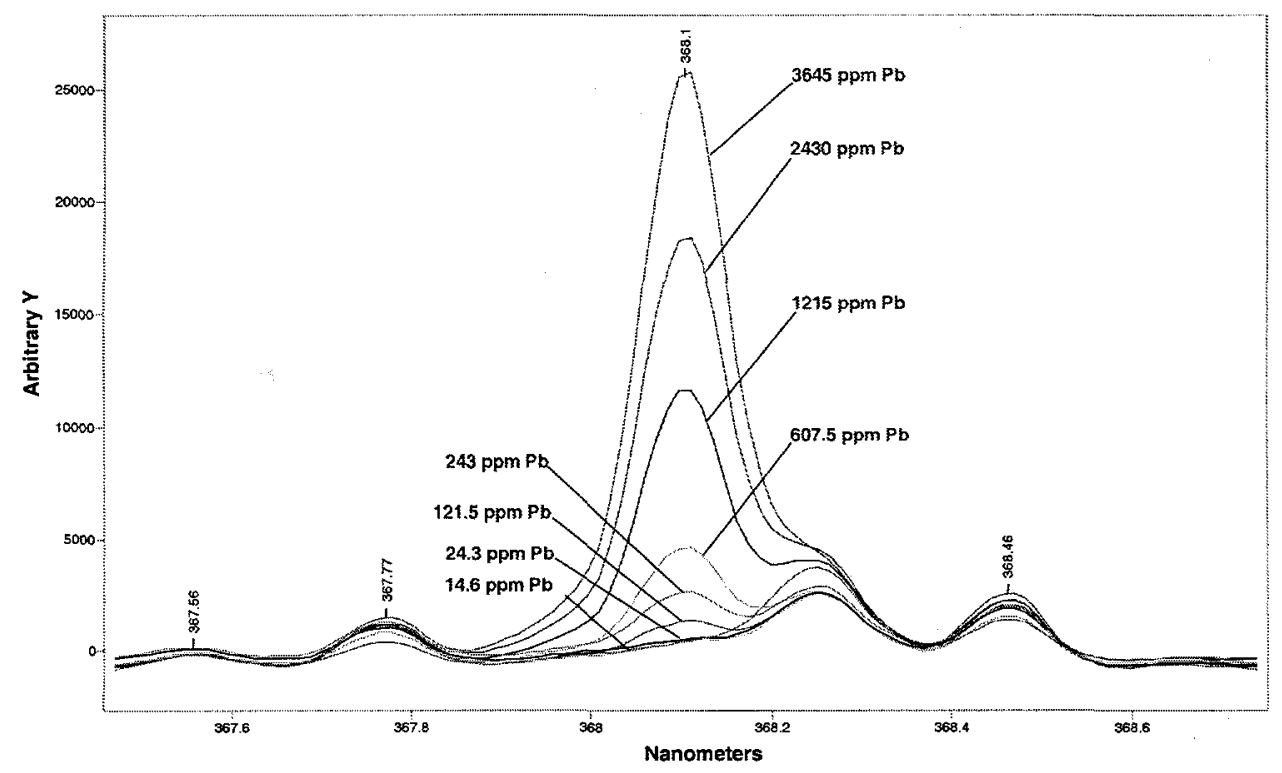

Figure 10. Region of interest for development of LIBS-SparkID calibration for $\mathrm{Pb}$ in soil.

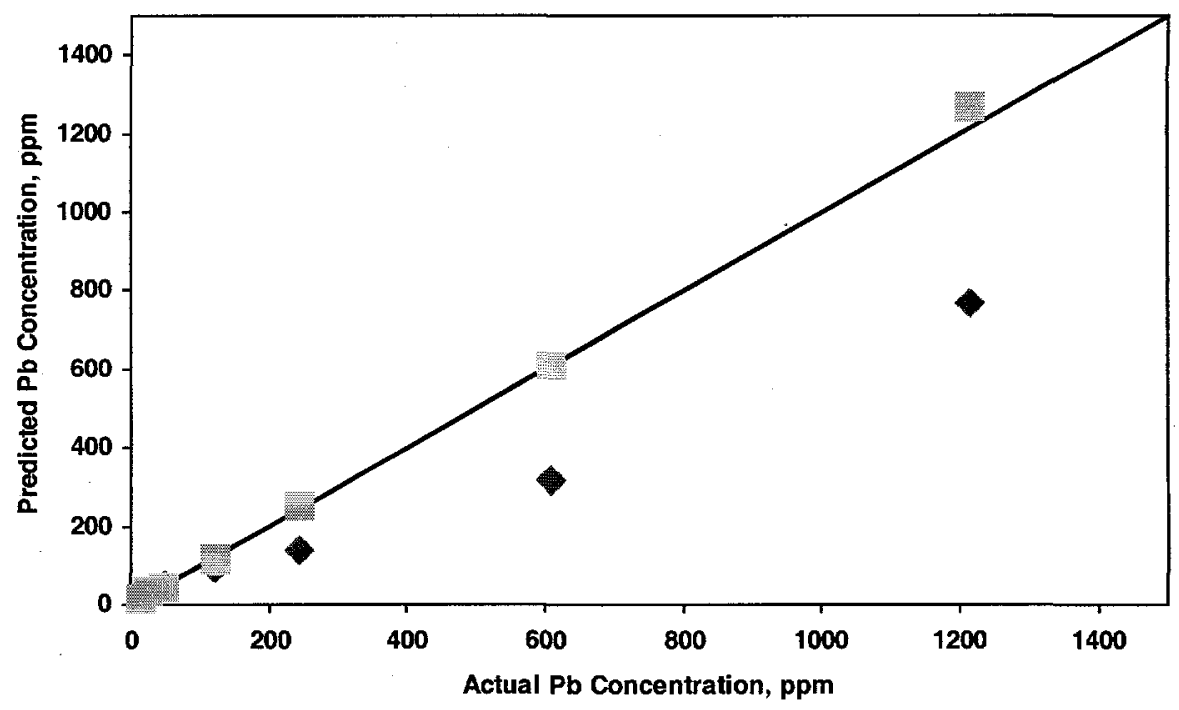

1:1 Reference Conv. Calib

Figure 11. Comparison of conventional and improved methods for prediction of $\mathrm{Pb}$ concentration in soil by LIBS-SparkID. 
the PLS method provides a more accurate prediction of $\mathrm{Pb}$ concentration in soil as measured with the LIBS-SparkID instrument.

\section{Task 2 - Validation of LIBS Calibration}

Calibrations have been developed for the LIBS-CPT and SparkID instruments for Cr and $\mathrm{Pb}$ in soil. Work to confirm the accuracy of the calibrations is under way at the time of this report. Validation of the $\mathrm{Cr}$ calibrations developed will be done using samples obtained from the Sandia Area 111 landfill. Excavation of the Sandia Area 111 landfill is currently under way, and Sandia personnel will make subsurface samples available to the EERC for conventional laboratory and LIBS analysis. Confirmation of the $\mathrm{Pb}$ calibration will be done by testing the calibration using soil samples containing lead contamination that are laboratory-spiked samples and/or actual samples obtained from the field.

\section{Task 3 - Development of Multivariate Models for Subsurface Matrix Effects on the LIBS Calibration}

As described above, calibrations for two different analytes in two different soil matrices on two different instruments were developed using conventional and multivariate techniques. In all cases, improvement over conventional approaches was achieved using PLS regression techniques. The LIBS-CPT instrument was applied in a field application at Sandia National Laboratory. Data analysis techniques were developed for the LIBS-CPT unit in field applications that allow data to be validated prior to prediction of analyte quantities and to provide an indication of data quality for a prediction of analyte concentration.

\section{Development of PLS Regression-Based Calibrations}

PLS regression is a technique that has been applied in molecular spectroscopy applications (22-41). However, it has not been widely applied in atomic spectroscopy because of the limited number of wavelength channels usually measured. For example, conventional atomic spectroscopic techniques such as ICP or GFAAS typically utilize a single analyte peak along with a baseline region to measure analyte concentration. For well-characterized sample matrices such as those encountered in the analytical laboratory, single-peak analyte prediction is more than adequate. In the case of field screening measurements for ex and in situ subsurface contamination characterization, little knowledge is obtained on the sample matrix prior to analysis. Therefore, application of more statistically robust methods such as PLS or principle components regression (PCR) can provide an added confidence to field screening measurements. Additionally, when applying field techniques such as LIBS, instant feedback as to the quality of the data being collected allows the proper weight to be applied to the data when using it to make decisions involving more detailed site characterization and cleanup. Field analytical instruments are typically operated by technicians who may not have the expertise to examine and interpret raw data while on-site. Conventional calibration techniques for LIBS call for expert personnel to ascertain the quality of data collected. Development of multivariate calibration techniques for LIBS allows instant feedback to the instrument operator that is easily interpreted by technicianlevel personnel on the quality of the data collected and the prediction of analyte quantities. 


\section{PLS Calibration Example - Estimation of Pb in Soil Using the LIBS-SparkID}

For example, a calibration for the SparkID instrument to estimate lead concentration in soil was developed as described above by collecting spectra from spiked soil samples. The regression technique applied was PLS. PLS has many inherent advantages compared to univariate regression methods (31-34). All relevant variables are included in the PLS model which implies that calibration even in the case of interferences is possible. PLS also makes possible outlier detection during the prediction of new unknown samples. Outlier detection identifies samples not accounted for by the PLS model, which will not be predicted, in contrast to the case in univariate calibration, where one cannot distinguish whether a sample is of the same kind as the calibration set or not. In PLS regression, independent variables (e.g., spectra) are arranged in a rectangular matrix $(\mathrm{X})$, where each row corresponds to a sample and each column to a specific wavelength. The dependent variable (e.g., concentration) is arranged in a vector ( $\mathrm{Y})$. The concentration vector $\mathrm{Y}$ has a number of elements equal to the number of rows (samples) in X. The result of the PLS algorithm is a model of $X$ given by a (low) number of latent variables, each being characterized by a score vector and a loading vector. The scores and loadings obtained from PLS allow any spectrum in the set to be approximately reconstructed, depending on the number of latent variables included in the spectrum reconstruction.

From a mathematical perspective, the loadings can be viewed as an orthonormal basis for the multidimensional vector space that describes the set of spectra (calibration space). The scores obtained for each sample spectrum are, thus, the amount of each loading needed to reconstruct the spectrum. In order to evaluate the number of latent variables needed to provide a PLS model for the sample set which estimates analyte quantities, the prediction residual error sum of squares (PRESS) is computed. Figure 12 shows the PRESS results for the $\mathrm{Pb}$ in soil calibration developed for the SparkID. The number of latent variables which may best approximate the calibration space is usually taken to be where the plot of PRESS versus number of latent variables reaches a global minimum. In the case of the $\mathrm{Pb}$ in soil model for the SparkID system, this is at 17 latent variables. Therefore, the calibration space contains 17 loadings (or dimensions). Scores for each sample are then computed by projection of each sample onto each loading. Thus each spectrum is then estimated by a sum of the loadings weighted by their respective scores. Once a calibration space is defined, estimation of analyte quantities in new samples is achieved by projection of the sample spectrum into the calibration space. Figure 11 shows the ability of the PLS model to estimate the quantity of $\mathrm{Pb}$ in soil using measurements from the LIBS-SparkID instrument. Figure 13 shows the first two loadings plotted against wavelength. The first latent variable may be interpreted as accounting for variations in the overall intensity of the emission spectrum. The second latent variable is accounting for most of the spectral variations from the amount of $\mathrm{Pb}$ in the soil sample being measured as evidenced by the two features corresponding to the $\mathrm{Pb}$ line emissions (see Figure 13).

\section{FUTURE WORK}

Continued work in this project will involve completion of Task 2 and development of improved calibration methods for application of LIBS in field screening applications. 


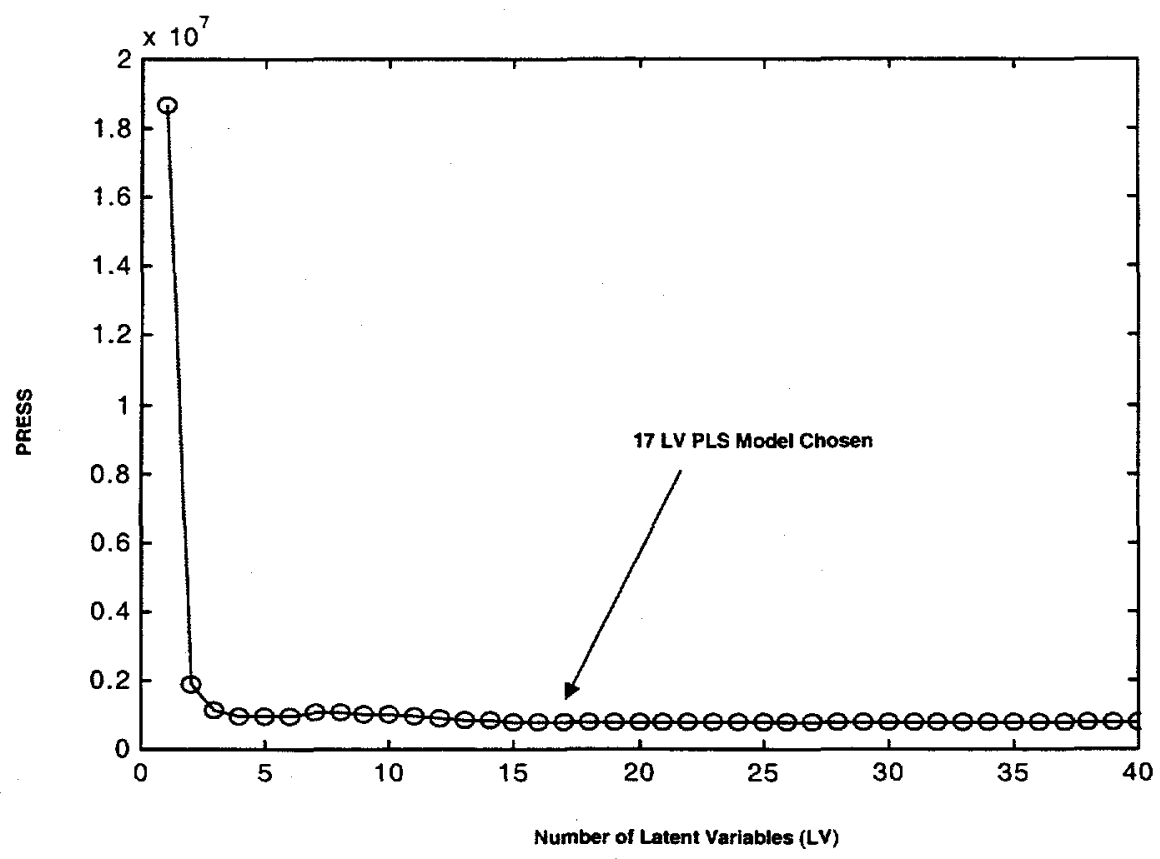

Figure 12. PRESS results for $\mathrm{Pb}$ in soil calibration by PLS.

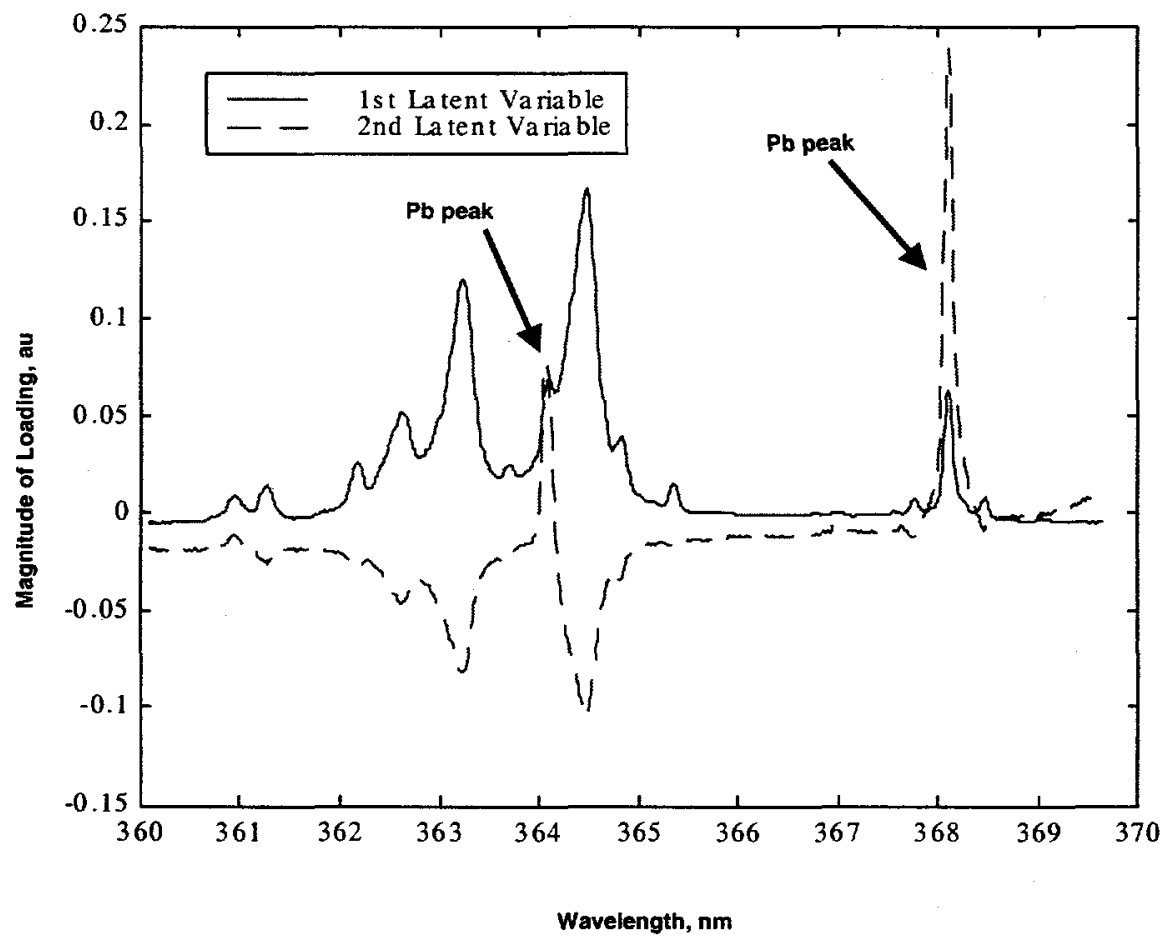

Figure 13. First two loadings from $\mathrm{PLS}$ regression of $\mathrm{Pb}$ calibration samples. 


\section{REFERENCES}

1. U.S. Department of Health and Human Services Agency for Toxic Substances and Disease. Registry Public Health Service; U.S. Government Printing Office: Washington, DC, 1994.

2. Cole, W.H. III; Enwall, R.E.; Raab, G.A.; Kuharic, W.H.; Englemann, W.H.; Eccles, L.A. Rapid Assessment of Superfund Sites for Hazardous Materials with X-Ray Fluorescence Spectrometry. Proceedings of the 2nd International Symposium on Field Screening Methods for Hazardous Wastes and Toxic Chemicals, 1991, pp 497-505.

3. Gonzalez, A.; Ortiz, M.; Campos, J. Determination of Sulfur Content in Steel by LaserProduced Plasma Atomic Emission Spectroscopy. Appl. Spectrosc. 1995, 49, 1632-1635.

4. Wachter, J.R.; Cremers, D.A. Determination of Uranium in Solution Using Laser-Induced Breakdown Spectroscopy. Appl. Spectrosc. 1987, 41, 1042-1048.

5. Cremers, D.A.; Radziemski, L.J.; Loree, T.R. Spectrochemical Analysis of Liquids Using the Laser Spark. Appl. Spectrosc. 1984, 38 (5), 721-729.

6. Radziemski, L.J.; Cremers, D.A. Spectrochemical Analysis Using Laser Plasma Excitation. In Laser-Induced Plasmas and Applications; Radziemski, L.J.; Cremers, D.A., Eds.; Marcel Dekker, Inc.: New York, 1989, pp 295-325.

7. Marquardt, B.J.; Goode, S.R.; Angel, S.M. In Situ Determination of Lead in Paint by Laser-Induced Breakdown Spectroscopy Using a Fiber-Optic Probe. Anal. Chem. 1996, 96, 977-981.

8. Grant, K.J.; Paul, G.L.; O'Neill, J.A. Quantitative Elemental Analysis of Iron Ore by Laser-Induced Breakdown Spectroscopy. Appl. Spectrosc. 1991, 45, 701-705.

9. Grant, K.J.; Paul, G.L.; O'Neill, J.A. Time-Resolved Laser-Induced Breakdown Spectroscopy of Iron Ore. Appl. Spectrosc. 1990, 44, 1711-1714.

10. Loree, T.R.; Radziemski, L.J.; Cremers, D.A. AES by LIBS May Help You. In ElectroOptical Systems Design; 1982, pp 35-41.

11. Hidalgo, M.; Martin, F.; Laserna, J.J. Laser-Induced Breakdown Spectrometry of Titanium Dioxide Antireflection Coatings in Photovoltaic Cells. Anal. Chem. 1996, 68, 1095-1100.

12. Pakhomov, A.V.; Nichols, W.; Borysow, J. Laser-Induced Breakdown Spectroscopy for Detection of Lead in Concrete. Appl. Spectrosc. 1996, 50, 880-884.

13. Multari, R.A.; Foster, L.E.; Cremers, D.A.; Ferris, M.J. Effect of Sampling Geometry on Elemental Emissions in Laser-Induced Breakdown Spectroscopy. Appl. Spectrosc. 1996, $50,1483-1499$. 
14. Kim, D.E.; Yoo, K.J.; Park, H.K.; Oh, K.J.; Kim, D.W. Quantitative Analysis of Aluminum Impurities in Zinc Alloy by Laser-Induced Breakdown Spectroscopy. Appl. Spectrosc. 1997, 51, 22-29.

15. Ho, W.F.; Ng, C.W.; Cheung, N.H. Spectrochemical Analysis of Liquids Using LaserInduced Plasma Emissions: Effects of Laser Wavelength. Appl. Spectrosc. 1997, 51, 8791.

16. Yamamoto, K.Y. ; Cremers, D.A.; Ferris, M. J.; Foster, L.E. Detection of Metals in the Environment Using a Portable Laser-Induced Breakdown Spectroscopy Instrument. Appl. Spectrosc. 1996, 50 (2), 222-232.

17. Eppler, A.S.; Cremers, D.A.; Hickmott, D.D.; Ferris, M.J.; Koskelo, A.C. Matrix Effects in the Detection of $\mathrm{Pb}$ and $\mathrm{Ba}$ in Soils Using Laser-Induced Breakdown Spectroscopy. Appl. Spectrosc. 1996, 50, 1175-1181.

18. Saggese, S.; Greenwell, R. Fiber Optic/Cone Penetrometer System for Subsurface Heavy Metals Detection. Kothari, V.P., Ed.; U.S. Department of Energy: Morgantown, 1995, pp 366-372.

19. Grisanti, A.A.; Timpe, R.C.; Foster, H.J.; Eylands, K.E.; Crocker, C.R. Cone Penetrometer for Subsurface Heavy Metals Detection. Semiannual Report for U.S. DOE FETC for the period Nov. 1, 1996 - March 31, 1997; EERC publication, 1997.

20. Grisanti, A.A.; Crocker, C.R. ; Timpe, R.C. Cone Penetrometer for Subsurface Heavy Metals Detection. Semiannual Report for U.S. DOE FETC for the period April 1 - Sept. 30, 1997; EERC publication, 1997.

21. Grisanti, A.A.; Crocker, C.R.; Timpe, R.C. Cone Penetrometer for Subsurface Heavy Metals Detection. Semiannual Report for U.S. DOE FETC for the period Oct. 1, 1997 March 31, 1998; EERC publication, 1998.

22. Westerholm, R.; Li, H. A Multivariate Statistical Analysis of Fuel-Related Polycyclic Aromatic Hydrocarbon Emissions from Heavy-Duty Diesel Vehicles. Environ. Sci. Technol. 1994, 28, 965-972.

23. Thomas, E.V.; Haaland, D.M. Comparison of Multivariate Calibration Methods for Quantitative Spectral Analysis. Anal. Chem. 1990, 62, 1091-1099.

24. Thomas, E.V. A Primer on Multivariate Calibration. Anal. Chem. 1994, 66 (15), 795A$804 \mathrm{~A}$.

25. Sekulic, S.; Seasholtz, M.B.; Wang, Z.; Kowalski, B.R. Nonlinear Multivariate Calibration Methods in Analytical Chemistry. Anal. Chem. 1993, 65, 835A-845A. 
26. Schrieve, G.D.; Ullman, A.H. Carbon Number Prediction from Herschel-Infrared Spectra Using Partial Least-Squares Regression. Appl. Spectrosc. 1991, 45, 713-714.

27. Ruyken, M.M.A.; Visser, J.A. On-Line Detection and Identification of Interferences in Multivariate Predictions of Organic Gases Using FT-IR Spectroscopy. Anal. Chem. 1995, $67,2170-2179$.

28. Li-shi, Y.; Levine, S.P. Fourier Transform Infrared Least-Squares Methods for the Quantitative Analysis of Multicomponent Mixtures of Airborne Vapors of Industrial Hygiene Concern. Anal. Chem. 1989, 61, 677-683.

29. Hong-kui, X.; Levine, S.P.; D'Arcy, J.B. Iterative Least-Squares Fit Procedures for the Identification of Organic Vapor Mixtures by Fourier Transform Infrared Spectrophotometry. Anal. Chem. 1989, 61, 2708-2714.

30. Hansen, W.G. Group Information and Application of PCA/PLS. In Near Infra-Red Spectroscopy-Bridging the Gap Between Data Analysis and NIR Applications, Hildrum, K.I., Isaksson, T.; Naes, T.; Tandberg, A., Eds.; Ellis, Horwood: New York, 1992, pp 2934.

31. Haaland, D.M.; Easterling, R.G.; Vopicka, D.A. Multivariate Least-Squares Methods Applied to the Quantitative Spectral Analysis of Multicomponent Samples. Appl. Spectrosc. 1985, 39 (1), 73-84.

32. Haaland, D.M.; Thomas, E.V. Partial Least-Squares Methods for Spectral Analyses. 1. Relation to Other Quantitative Calibration Methods and the Extraction of Qualitative Information. Anal. Chem. 1988, 60, 1193-1202.

33. Haaland, D.M.; Thomas, E.V. Partial Least-Squares Methods for Spectral Analyses. 2. Application to Simulated and Glass Spectral Data. Anal. Chem. 1988, 60, 1202-1208.

34. Geladi, P.; Kowalski, B.R. Partial Least-Squares Regression: A Tutorial. Anal. Chim. Acta 1986, 185, 1-17.

35. Garrido Frenich, A.; Martinez Galera, M.; Martinez Vidal, J.L.; Gil Garcia, M.D. Partial Least-Squares and Principal Component Regression of Multi-Analyte High-Performance Liquid Chromatography with Diode-Array Detection. J.Chromatogr. 1996, 727, 27-38.

36. Garcia, F.X.; De Lima, L.; Medina, J.C. Determination of Methanol and Methyl tert-Butyl Ether in Gasoline by Infrared Spectroscopy Using the CIRCLE Cell and Multivariate Calibration. Appl. Spectrosc. 1993, 47, 1036-1039.

37. Frank, I.E.; Friedman, J.H. A Statistical View of Some Chemometrics Regression Tools. Technometrics 1993, 35, 109-135. 
38. Espinosa-Mansilla, A.; Salinas, F.; del Olmo, M.; de Orbe Paya, I. Determination of Synthetic Food Antioxidants in Multicomponent Mixtures Using UV-Visible Spectrophotometry and Partial Least-Squares Calibration. Appl. Spectrosc. 1996, 50, 449453.

39. Cooper, J.B.; Wise, K.L.; Groves, J.; Welch, W.T. Determination of Octane Numbers and Reid Vapor Pressure of Commericial Petroleum Fuels Using FT-Raman Spectroscopy and Partial Least-Squares Regression Analysis. Anal. Chem. 1995, 67, 4096-4100.

40. Cooper, J.B.; Flecher, P.E.; Vess, T.M.; Welch, W.T. Remote Fiber-Optic Raman Analysis of Xylene Isomers in Mock Petroleum Fuels Using a Low-Cost Dispersive Instrument and Partial Least-Squares Regression Analysis. Appl. Spectrosc. 1995, 49, 586-592.

41. Conzen, J.P.; Burck, J.; Ache, H.J. Determination of Chlorinated Hydrocarbons in Water by Fiber-Optic Evanescent Wave Spectroscopy and Partial Least-Squares Regression Fresenius' J. Anal. Chem. 1994, 348, 501-505. 